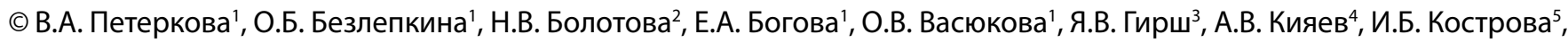
О.А. Малиевский ${ }^{6}$, Е.Г. Михайлова ${ }^{7}$, П.Л. Окороков ${ }^{1 *}$, Е.Е. Петряйкина ${ }^{8}$, Т.Е. Таранушенко ${ }^{9}$, Е.Б. Храмова ${ }^{10}$

'Национальный медицинский исследовательский центр эндокринологии, Москва, Россия

${ }^{2}$ Саратовский государственный медицинский университет им. В.И. Разумовского, Саратов, Россия

${ }^{3}$ Сургутский государственный университет ХМАО-Югры, Сургут, Россия

4Уральский государственный медицинский университет, Екатеринбург, Россия

${ }^{5}$ Детская республиканская клиническая больница им. Н.М. Кураева, Махачкала, Россия

${ }^{6}$ Башкирский государственный медицинский университет, Уфа, Россия

${ }^{7}$ Детская городская клиническая больница №1 им. Н.Н. Ивановой, Самара, Россия

${ }^{8}$ Российская детская клиническая больница, Москва, Россия

${ }^{9}$ Красноярский государственный медицинский университет имени профессора В.Ф. Войно-Ясенецкого, Красноярск, Россия

${ }^{10}$ Тюменский государственный медицинский университет, Тюмень, Россия

Ожирение у детей является актуальной проблемой детской эндокринологии в связи с широкой распространенностью, развитием метаболических нарушений и их устойчивым трекингом во взрослую жизнь. Разработанные клинические рекомендации являются основным рабочим инструментом практикующего врача. В них кратко и структурированно изложены основные сведения об эпидемиологии и современной классификации ожирения, методах его диагностики и лечения, базирующихся на принципах доказательной медицины.

КЛЮЧЕВЫЕ СЛОВА: кЛинические рекомендации; ожирение; дети.

\title{
CLINICAL GUIDELINES «OBESITY IN CHILDREN»
}

(c) Valentina A. Peterkova', Olga B. Bezlepkina', Nina V. Bolotova², Elena A. Bogova', Olga V. Vasyukova', Yana V. Girsh³, Alexey V. Kiyaev ${ }^{4}$, Irina B. Kostrova ${ }^{5}$, Oleg A. Malievskiy ${ }^{6}$, Evgeniia G. Mikhailova ${ }^{7}$, Pavel L. Okorokov ${ }^{1 *}$, Elena E. Petryaykina ${ }^{8}$, Tatiana E. Taranushenko' ${ }^{9}$ Elena B. Khramova ${ }^{10}$

'Endocrinology Research Center, Moscow, Russia

${ }^{2}$ Saratov State Medical University named after V. I. Razumovsky, Saratov, Russia

${ }^{3}$ Surgut State University, Surgut, Russia

${ }^{4}$ Ural State Medical University, Ekaterinburg, Russia

${ }^{5}$ N.M. Kuraev Children's Republican Clinical Hospital, Makhachkala, Russia

${ }^{6}$ Bashkir State Medical University, Ufa, Russia

${ }^{7}$ Children's City Clinical Hospital № 1 named after N. N. Ivanova, Samara, Russia

${ }^{8}$ Russian Children's Clinical Hospital, Pirogov Russian National Research Medical University, Moscow, Russia

${ }^{9}$ Krasnoyarsk State Medical University named after V. F. Voino-Yasenetsky, Krasnoyarsk, Russia

${ }^{10}$ Tyumen State Medical University, Tyumen, Russia

Childhood obesity is an urgent problem of pediatric endocrinology due to the widespread occurrence, the development of metabolic complications and their steady tracking into adulthood. The developed clinical guidelines are the main working tool of the practitioner. They briefly and structurally present the main information about the epidemiology and modern classification of obesity, methods of its diagnosis and treatment based on the principles of evidence-based medicine.

KEYWORDS: clinical guidelines; obesity; children.

\section{СПИСОК СОКРАЩЕНИЙ}

АД - артериальное давление

АГ - артериальная гипертензия

АлАТ - аланинаминотрансфераза

АсАТ - аспартатаминотрансфераза

ДАД - диастолическое артериальное давление

ИМт - индекс массы тела
ИР - инсулинорезистентность
ИРИ - иммунореактивный инсулин
КТ - компьютерная томография
ЛПВП - липопротеиды высокой плотности
лПНП - липопротеиды низкой плотности
МРТ - магнитно-резонансная томография
НАЖБП - неалкогольная жировая болезнь печени
ЖКБ - желчнокаменная болезнь 


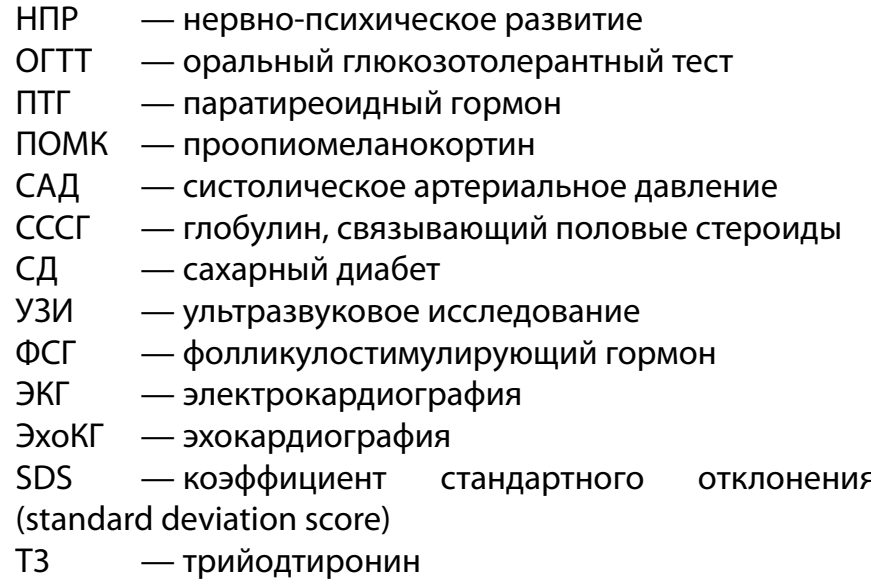

\section{ТЕРМИНЫ И ОПРЕДЕЛЕНИЯ}

Простое (конституционально-экзогенное, идиопатическое) ожирение - ожирение, связанное с избыточным поступлением калорий в условиях гиподинамии и наследственной предрасположенности.

Гипоталамическое ожирение - ожирение, связанное с наличием и лечением опухолей гипоталамуса и ствола мозга, лучевой терапией опухолей головного мозга и гемобластозов, травмой черепа или инсультом.

Ятрогенное ожирение - ожирение, связанное с длительным приемом лекарственных препаратов (глюкокортикоидов, антидепрессантов и др.).

Синдромальное ожирение - ожирение, развивающееся при хромосомных и других генетических синдромах (Прадера-Вилли, хрупкой Х-хромосомы, Альстрема, Кохена, Дауна, псевдогипопаратиреозе и др.).

Моногенное ожирение - ожирение, развивающееся вследствие мутации в гене (лептин, рецептор лептина, рецептор меланокортинов 3 и 4 типа, проопиомеланокортин (ПОМК), проконвертаза 1 типа, рецептор нейротрофического фактора - тропомиозин-связанная киназа В).

\section{1. КРАТКАЯ ИНФОРМАЦИЯ ПО ЗАБОЛЕВАНИЮ ИЛИ СОСТОЯНИЮ (ГРУППЕ ЗАБОЛЕВАНИЙ или состояний)}

1.1. Определение заболевания или состояния (группы заболеваний или состояний).

Ожирение - это гетерогенная группа наследственных и приобретенных заболеваний, связанных с избыточным накоплением жировой ткани в организме [1, 2].

1.2. Этиология и патогенез заболевания или состояния (группы заболеваний или состояний).

Ожирение относится к многофакторным заболеваниям, возникающим в результате определенного взаимодействия генетических и негенетических причин. Роль «наследственности» в развитии ожирения доказывается разной частотой встречаемости данного заболевания в различных этнических группах и более высокой конкордантностью в развитии патологии у однояйцовых близнецов.

Самый частый вид ожирения, связанный с избыточным поступлением калорий в условиях гиподинамии и наследственной предрасположенности, - конституционально-экзогенное (простое, идиопатическое) ожирение.
Генетическая составляющая является определяющей для моногенных и некоторых синдромальных форм ожирения [3]. Значительно реже ожирение в детском и подростковом возрасте связано с применением лекарственных препаратов (например, глюкокортикостероидов, антидепрессантов, нейролептиков (антипсихотиков), противоэпилептических препаратов) или наличием заболеваний и состояний (опухолей гипоталамуса и ствола мозга, лучевой терапией опухолей головного мозга и гемобластозов, травмой черепа, инсультом, гиперкортицизмом, гипотиреозом и другими нейроэндокринными заболеваниями, хромосомными нарушениями).

\section{3. Эпидемиология заболевания или состояния} (группы заболеваний или состояний).

По данным Всемирной организации здравоохранения (ВО3), более миллиарда человек на планете имеют лишний вес, в 2014 г. зарегистрировано более 500 млн больных ожирением. При этом 30 млн детей и подростков Европейского региона имеют избыточную массу тела и 15 млн - ожирение (Health in the European Union. Trends and analysis. ВО3, 2009). Одной из самых негативных тенденций можно назвать увеличение числа избыточной массы тела у детей младшего возраста. По оценке ВО3, существующие тенденции могут обусловить наличие ожирения у 70 млн детей до 5 лет к 2025 г. [4].

Одно из наиболее крупных популяционных исследований в Российской Федерации, проведенное в 2004 г., включившее 13700 детей 6-18 лет из 6 регионов (Тверская, Ростовская, Тульская, Брянская, Калужская, Орловская области и остров Сахалин) выявило избыточную массу тела у детей в 5,5-11,8\% случаев, а ожирение у 5,5\% детей, проживающих в сельской местности, и 8,5\% - в городской [5]. Средний возраст обследуемых составил 13 лет. Исследование 2017-2018 гг., проведенное в г. Москве в рамках программы COSI (Childhood Obesity Surveillance Initiative - инициатива Европейского регионального бюро ВОЗ по эпиднадзору за детским ожирением), включившее 2166 детей 7-летнего возраста, выявило наличие избыточной массы тела у $27 \%$ мальчиков и $22 \%$ девочек, а ожирение - у $10 \%$ и $6 \%$ детей соответственно [6].

\section{4. Особенности кодирования заболевания или} состояния (группы заболеваний или состояний) по Международной статистической классификации болезней и проблем, связанных со здоровьем

- Е66.0 Ожирение, обусловленное избыточным поступлением энергетических ресурсов.

- Е66.1 Ожирение, вызванное приемом лекарственных средств.

- Е66.2 Крайняя степень ожирения, сопровождающаяся альвеолярной гиповентиляцией.

- Е66.8 Другие формы ожирения.

- E66.9 Ожирение неуточненное.

- E67.8 Другие уточненные формы избыточности питания.

1.5. Классификация заболевания или состояния (группы заболеваний или состояний).

Классификация ожирения у детей (В.А. Петеркова, О.В. Васюкова, 2014 [1, 2]). 


\section{1. По этиологии:}

- простое (конституционально-экзогенное, идиопатическое);

- гипоталамическое;

- ожирение при эндокринных заболеваниях (гиперкортицизме, гипотиреозе и др.);

- ожирение ятрогенное;

- моногенное ожирение;

- синдромальное ожирение.

2. По наличию осложнений и коморбидных состояний:

- нарушения углеводного обмена (нарушение толерантности к глюкозе, нарушение гликемии натощак, инсулинорезистентность, сахарный диабет);

- неалкогольная жировая болезнь печени (жировой гепатоз и стеатогепатит как наиболее часто встречающиеся у детей состояния);

- дислипидемия;

- артериальная гипертензия;

- задержка полового развития;

- ускоренное половое развитие;

- синдром гиперандрогении;

- синдром апноэ-гипопноэ;

- нарушения опорно-двигательной системы (болезнь Блаунта, остеоартрит, спондилолистез и др.);

- желчнокаменная болезнь.

3. По степени ожирения:

- SDS ИMT 2,0-2,5 - I степень;

- SDS ИMT 2,6-3,0 - II степень;

- SDS ИМТ 3,1-3,9 - III степень;

- $\operatorname{SDS}$ ИМТ $\geq 4,0$ - морбидное.

1.6. Клиническая картина заболевания или состояния (группы заболеваний или состояний).

Клиническая картина определяется этиопатогенетической формой ожирения. Самая многочисленная группа, на долю которой приходится до 98-99\% всех случаев ожирения, - простое (конституционально-экзогенное, идиопатическое) ожирение. Дебют заболевания чаще всего в возрасте после 5 лет или в периоде полового созревания. Как правило, ожирение прогрессирует постепенно, на фоне хороших (часто ускоренных) темпов роста. Наличие стрий, фолликулярного кератоза, полифагии, черного акантоза, артериальной гипертензии и других не всегда коррелирует со степенью ожирения. Характерно наличие избыточной массы тела и ожирения у родственников (родители, бабушки, дедушки). Гипоталамическое ожирение в большинстве случаев отличается быстропрогрессирующим характером, развивается после оперативного вмешательства (лучевой терапии), реже - предшествует периоду постановки диагноза. В случае краниофарингиомы для большинства пациентов характерно замедление темпов роста; для глиом - симптомы преждевременного полового развития; неврологические жалобы (головные боли, нарушение зрения) зависят от локализации и прогрессии опухоли. У детей с гипоталамическим ожирением часто отмечаются нарушения ритма сна и бодрствования и поведенческие нарушения. При моногенных формах ожирение дебютирует в первые месяцы и годы жизни, для большинства синдромальных форм характерна задержка психомоторного развития.
- Скрининг на наличие моногенных и синдромальных форм ожирения рекомендуется детям с ранним (до 5 лет жизни) ожирением на фоне выраженной полифагии, особенно при наличии выраженного ожирения в семейном анамнезе [1, 3, 21].

Уровень убедительности рекомендаций С (уровень достоверности доказательств - 5).

Комментарии. Синдромальные формы ожирения характеризуются ранним дебютом ожирения и его быстрым прогрессированием. Для большинства синдромальных форм характерны задержка нервно-психического развития от умеренной до тяжелой степени выраженности, наличие дисморфических признаков и органоспецифических аномалий развития. К настоящему времени изучено не менее 30 синдромов, ассоциированных с ожирением (наиболее известные приведены в табл. 1).

Моногенные формы ожирения (табл. 2) встречаются крайне редко, отличаются ранним дебютом (с первых месяцев жизни до 1 года), полифагией. Для большинства пациентов характерно нормальное нервно-психическое развитие.

Нейроэндокринные заболевания являются редкими причинами ожирения в детском возрасте и отличаются характерными клиническими признаками. Так, для гиперкортицизма характерно снижение темпов роста наряду с прогрессирующим ожирением, тогда как появление сухости кожных покровов, непереносимости холода, быстрой утомляемости может свидетельствовать о наличии гипотиреоза.

Общие принципы дифференциальной диагностики различных форм ожирения представлены в приложении (рис. 1).

\section{2. ДИАГНОСТИКА ЗАБОЛЕВАНИЯ ИЛИ СОСТОЯНИЯ}

Критерии установления диагноза/состояния.

В качестве диагностического критерия избыточной массы тела и ожирения у детей рекомендовано определение величины стандартных отклонений индекса массы тела (SDS ИMT). С учетом рекомендаций ВО3, ожирение у детей и подростков от 0 до 19 лет следует определять как ИМТ, равный или более $+2,0$ SDS ИMT, а избыточную массу тела - от +1,0 до +2,0 SDS ИМТ. Нормальная масса тела диагностируется при значениях ИМТ в пределах $\pm 1,0$ SDS ИMT $[1,5,7]$.

\section{1. Жалобы и анамнез.}

При сборе анамнеза выявляют вес при рождении, возраст дебюта ожирения, психомоторное развитие, наследственный анамнез по ожирению (включая рост и вес родителей), сахарному диабету 2 типа и сердечно-сосудистым заболеваниям, динамику роста и веса, наличие неврологических жалоб (головные боли, нарушение зрения).

\section{2. Физикальное обследование.}

- Всем детям с ожирением и избыточной массой тела для определения наличия и степени ожирения рекомендуется проводить измерения роста, SDS роста, веса с расчетом SDS ИMT, окружности талии, оценивать характер распределения подкожной жировой клетчатки $[1,7,15,37,54]$.

Уровень убедительности рекомендаций С (уровень достоверности доказательств - 5). 


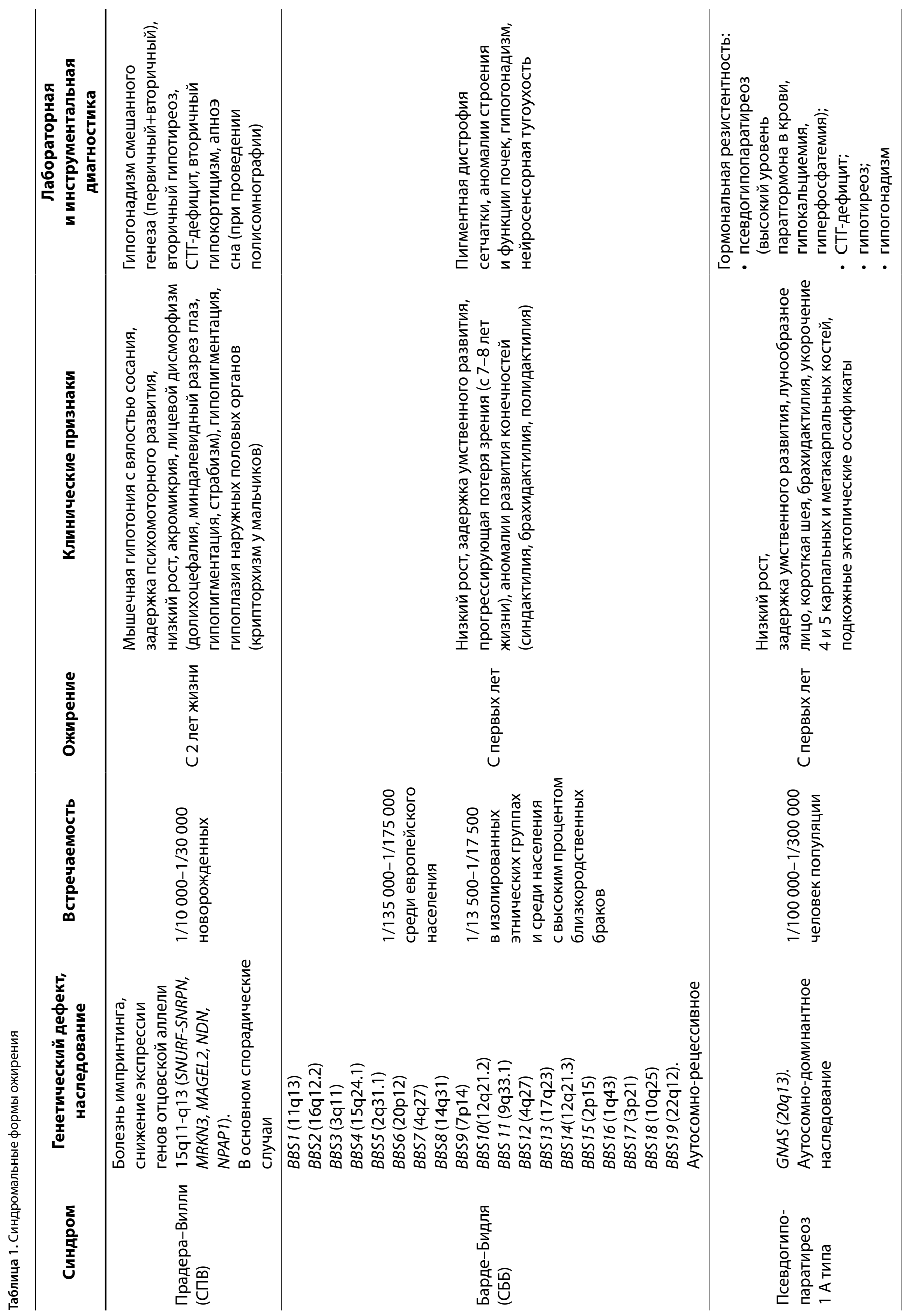




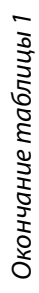

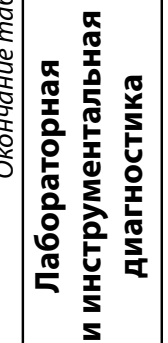

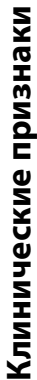

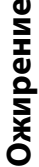

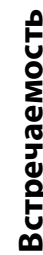

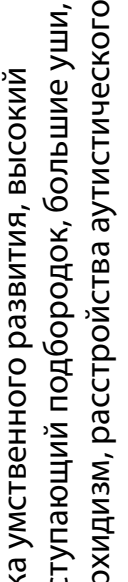

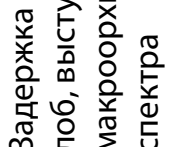

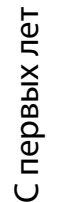

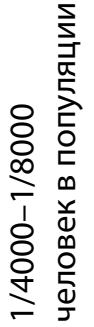
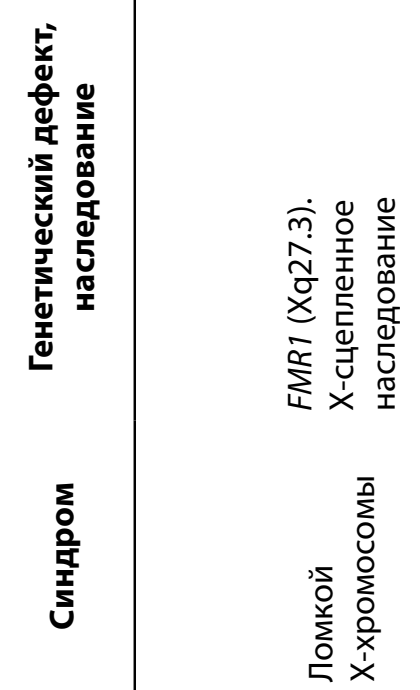

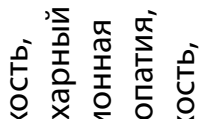

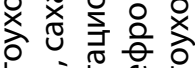

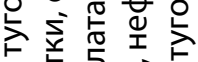

西

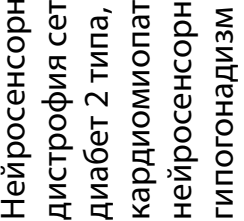

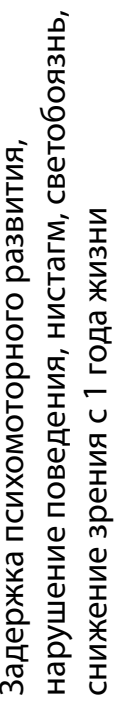

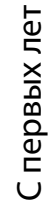

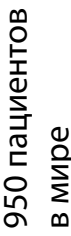

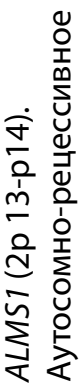

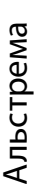

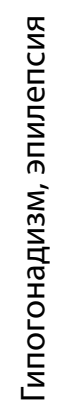

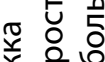

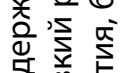

m

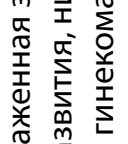

을 응

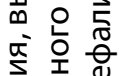

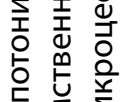

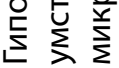

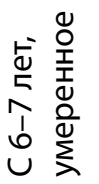

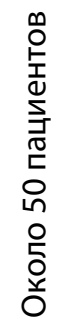

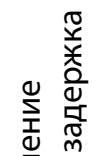

잉

है

ऽ

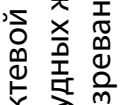

응

든 뜬

常 点

본

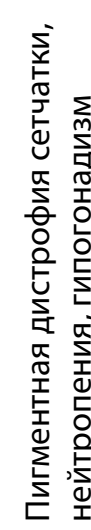

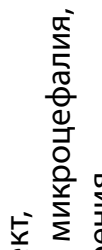

产

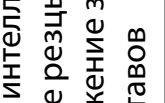

ग

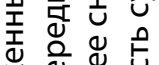

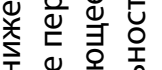

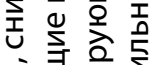

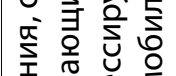

要

든 음을 돈

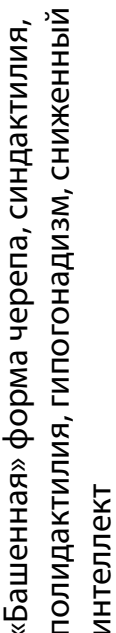

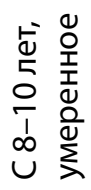

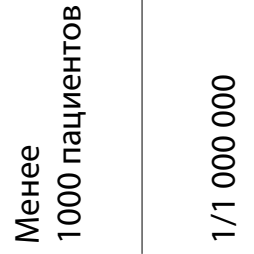

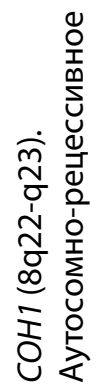

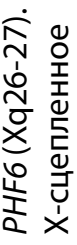

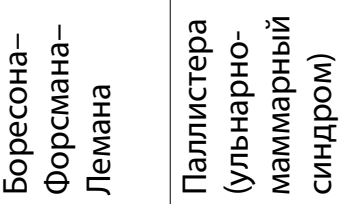

$\frac{\pi}{0}$
$\frac{0}{2}$
$\frac{1}{4}$
$\frac{0}{0}$
$\frac{2}{0}$ 


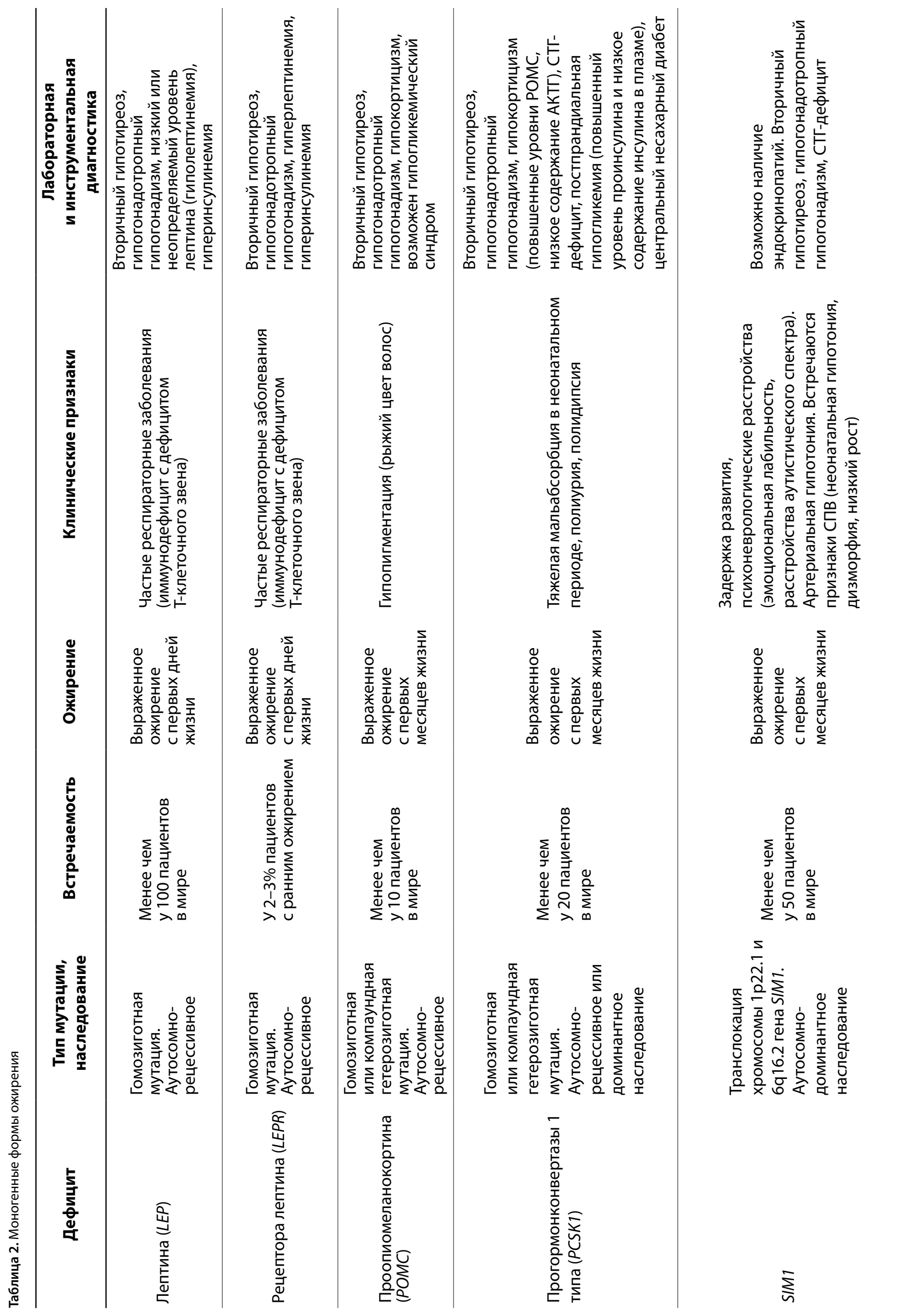



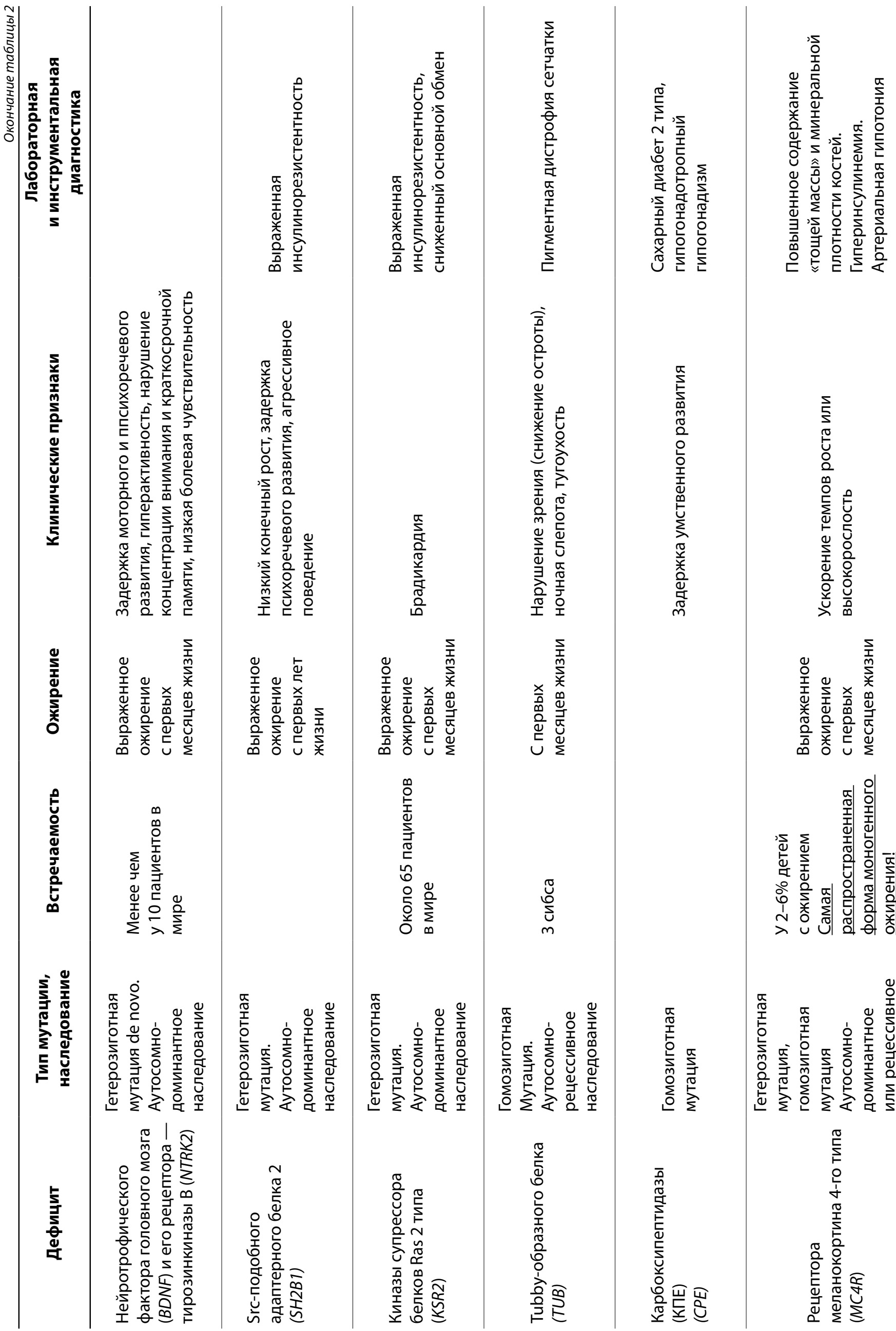

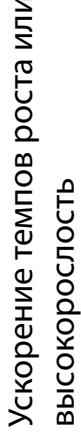
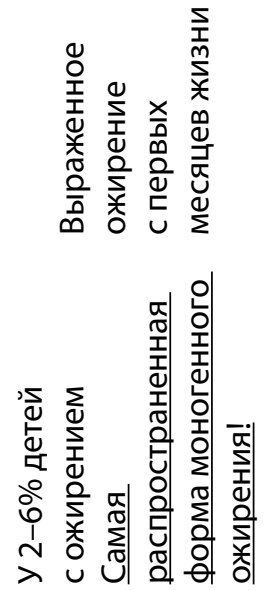
- $\quad$ Всем детям с ожирением и избыточной массой тела для выявления артериальной гипертензии рекомендуется проводить измерение артериального давления (АД) и оценивать его с учетом пола, возраста и роста $[1,8,9,15,21]$.

Уровень убедительности рекомендаций С (уровень достоверности доказательств - 5).

- Для диагностики наличия артериальной гипертензии, выявленной при обычном измерении, рекомендуется проведение суточного мониторирования АД [8, $9,15,22]$.

Уровень убедительности рекомендаций С (уровень достоверности доказательств - 5).

- Всем детям с ожирением и избыточной массой тела для скрининга ассоциированных с ожирением заболеваний рекомендуется определять наличие и характер стрий, фолликулярного кератоза, acanthosis nigricans, андрогензависимой дермопатии (у девочек - гирсутим, акне, жирная себорея) [1, 15, 21, 37].

Уровень убедительности рекомендаций С (уровень достоверности доказательств - 5).

- Всем детям с ожирением и избыточной массой тела для объективной оценки состояния ребенка рекомендуется оценивать стадию полового развития по шкале Таннера [1, 15, 21, 37].

Уровень убедительности рекомендаций С (уровень достоверности доказательств - 5).

- Всем детям с ожирением и избыточной массой тела для выявления генетических синдромов, ассоциированных с ожирением, рекомендуется выявлять характерные специфические фенотипические особенности (см. табл. 2) [1, 15, 21, 54].

Уровень убедительности рекомендаций С (уровень достоверности доказательств - 5).

\section{3. Лабораторные диагностические исследования.}

- Всем пациентам с ожирением с целью скрининга осложнений рекомендовано исследование биохимического анализа крови для выявления нарушений липидного обмена, определение активности АлАТ и АсАТ в крови в сочетании с ультразвуковым исследованием органов брюшной полости (печени) [8, 9, $10,15,22,55]$.

Уровень убедительности рекомендаций С (уровень достоверности доказательств - 5).

Комментарии. Диагноз дислипидемии устанавливается при наличии 2 и более «высоких» и/или «низких» показателей: холестерин 25,2 ммоль/л; триглицериды $>1,3$ ммоль/л (для детей до 10 лет); $\geq 1,7$ (для детей старше 10 лет) ммоль/л; уровень липопротеидов высокой плотности (ЛПВП) $\leq 0,9$ (мальчики) и $\leq 1,03$ (девочки) ммоль/л; уровень липопротеидов низкой плотности (ЛПНП) 23,0 ммоль/л. Активность АлАТ, превышающая верхнюю границу нормы, установленной для данной лаборатории, у детей с признаками неалкогольной жировой болезни печени (НАЖБП) по УЗИ при отсутствии других причин синдрома цитолиза (вирусные, метаболические поражения печени и др.) расценивается как проявление стеатогепатита [10]. В сомнительных случаях достоверная диагностика неалкогольного стеатогепатита возможна только после морфологического исследования ткани печени.
- Всем пациентам с ожирением старше 10 лет для выявления нарушений углеводного обмена рекомендовано проведение орального глюкозотолерантного теста (ОГТТ) с определением глюкозы натощак и через 120 минут [56-58].

Уровень убедительности рекомендаций С (уровень достоверности доказательств - 5).

Комментарии. Нецелесообразно исследование уровня глюкозы в крови с помощью глюкометров для диагностики нарушений углеводного обмена, так как глюкометры не обладают достаточной точностью для убедительной постановки диагноза и могут привести к ошибкам при диагностике [56]. При клинически манифестном сахарном диабете (СД) проводить ОГТТ не рекомендуется, нарушения углеводного обмена можно диагностировать с помощью показателей гликемии натощак, постпрандиально или в течение дня, исследованием уровня гликированного гемоглобина. Проведение ОГТТ детям с ожирением, не достигшим 10 лет, показано при наличии у ребенка дополнительных факторов риска: клинических признаков инсулинорезистентности (акантоз), гестационного диабета у матери, СД у родственников 1-й и 2-й линии родства, при подозрении на врожденные синдромы, связанные с ранним развитием СД и др., и в каждом случае решается индивидуально [57].

\section{4. Инструментальные диагностические} исследования.

- Для скрининга НАЖБП и желчнокаменной болезни у детей и подростков с ожирением рекомендовано проведение УЗИ органов брюшной полости (комплексного) [1, 10, 55, 56].

Уровень убедительности рекомендаций С (уровень достоверности доказательств - 5).

Комментарии. УЗИ помогает выявить стеатоз печени и наличие калькулезного холецистита с достаточно высокой точностью. Диагностическими ультразвуковыми признаками жирового гепатоза являются гепатомегалия, неоднородность паренхимы и ослабление ультразвукового сигнала в дистальных отделах печени, обеднение сосудистого рисунка.

- Проведение ночной полисомнографии рекомендуется детям и подросткам с ожирением при клинических признаках синдрома обструктивного апноэ во сне: повышенная сонливость в дневное время, храп во время сна, остановки дыхания во время сна $[1,15,21$, 59].

Уровень убедительности рекомендаций С (уровень достоверности доказательств - 5).

Комментарии. Ночная полисомнография является золотым стандартом диагностики обструктивного апноэ во сне.

\section{5. Иные диагностические исследования}

- Всем детям и подросткам с ожирением и избыточной массой тела рекомендуется проводить оценку фактического питания с использованием метода 24-часового (суточного) воспроизведения питания с помощью пищевого дневника для назначения диетотерапии или ее коррекции $[15,21]$.

Уровень убедительности рекомендаций С (уровень достоверности доказательств - 5). 
Комментарии. Для оценки фактического питания и изменений пищевого статуса используются различные методы, в том числе метод 24-часового (суточного) воспроизведения питания (ведение пищевого дневника) и метод анализа частоты потребления пищи. Метод регистрации потребляемой пищи посредствам пищевого дневника является наиболее точным и достоверным в оценке фактического питания. Кего недостаткам можно отнести трудоемкость метода и влияние на привычное питание пациента.

- Проведение дополнительных исследований (исследование гормонального профиля, МРТ головного мозга, молекулярно-генетические и цитогенетические методы) у детей и подростков с ожирением рекомендовано только при подозрении на гипоталамическую, синдромальную, эндокринную или моногенную формы ожирения [1, 9, 15, 21].

Уровень убедительности рекомендаций С (уровень достоверности доказательств - 5).

- Консультации профильных специалистов (врача-кардиолога, врача акушера-гинеколога, врачаофтальмолога, медицинского психолога, врачапсихиатра и др.) рекомендованы детям и подросткам с избыточной массой тела и ожирением при выявлении профильных сопутствующих заболеваний - артериальной гипертензии, нарушений менструального цикла, депрессии и др. [1, 9, 15, 21].

Уровень убедительности рекомендаций С (уровень достоверности доказательств - 5).

- Оценка инсулинорезистентности (ИР) у детей и подростков с ожирением проводится по строгим показаниям и не рекомендуется в рутинной клинической практике [1, 15, 21].

Уровень убедительности рекомендаций С (уровень достоверности доказательств - 5).

Комментарии. Золотым стандартом диагностики ИР являются эугликемический и гипергликемический клэмп, а также внутривенный глюкозотолерантный тест с частыми заборами крови, оцениваемый с помощью минимальной модели Бергмана $[18,19]$. К сожалению, эти тесты неприменимы в повседневной практике, так как они весьма продолжительны, дорогостоящи и инвазивны, требуют специально обученного медицинского персонала и сложной статистической обработки результатов. В повседневной практике для оценки ИР при ожирении у детей и подростков наибольшей диагностической значимостью обладают значения стимулированного выброса инсулина и индекса Matsuda, определяемые по данным глюкозотолерантного теста [20]. Значения индекса ниже 2,6 свидетельствуют о наличии ИР $[53,60]$. К показаниям для проведения глюкозотолерантного теста с оценкой ИР можно отнести наличие у пациента ранее выявленных нарушений углеводного обмена, отягощенный семейный анамнез (по СД 2 типа, гиперандрогении и др.), наличие объективных маркеров ИР - acanthosis nigricans или выраженная гиперпигментация кожных складок шеи, подмышечных или паховой областей, клинические признаки гиперандрогении.

- Детям и подросткам с ожирением и избыточной массой тела рекомендуется, по возможности, определение процентного соотношения воды, мышечной и жировой ткани с помощью анализатора состава тела человека $[11-15,63]$.
Уровень убедительности рекомендаций С (уровень достоверности доказательств - 4).

Комментарии. Биоимпедансный анализ состава тела основан на измерении электрического сопротивления тканей (импеданса) при прохождении через них низкоинтенсивного электрического тока и позволяет оценить количество жировой и тощей массы, а также воды в организме (композиционный состав тела). Исследование целесообразно для поддержания мотивационной приверженности пациента к лечению, оценки изменения композиционных параметров тела в динамике, но не является обязательным.

- Для персонификации проводимой диетотерапии детям и подросткам с ожирением и избыточной массой тела целесообразно, по возможности, исследование основного обмена с помощью метода непрямой респираторной калориметрии [16, 17].

Уровень убедительности рекомендаций С (уровень достоверности доказательств - 5).

Комментарии. Основным методом исследования основного обмена в настоящее время является непрямая респираторная калориметрия. Данная методика рекомендована Американской ассоциацией диетологов и нутрициологов и Американской академией педиатрии в качестве предпочтительного метода для оценки основного обмена у детей и подростков. Вместе с тем, учитывая дороговизну метода, необходимость дополнительного обучения врача проведению данного исследования, оценка основного обмена возможна на базе крупных центров с наличием специализированного эндокринологического отделения; не является обязательной.

\section{3. ЛЕЧЕНИЕ, ВКЛЮЧАЯ МЕДИКАМЕНТОЗНУЮ И НЕМЕДИКАМЕНТОЗНУЮ ТЕРАПИИ, ДИЕТОТЕРАПИЮ, ОБЕЗБОЛИВАНИЕ, МЕДИЦИНСКИЕ ПОКАЗАНИЯ И ПРОТИВОПОКАЗАНИЯ К ПРИМЕНЕНИЮ МЕТОДОВ ЛЕЧЕНИЯ}

Изменение образа жизни (диетотерапия, расширение физической активности и коррекция пищевого поведения) у детей и подростков с ожирением или избыточной массой тела, а также членов их семьи составляет основу терапии ожирения и его профилактики. В случае неэффективности модификации образа жизни возможно использование фармакологических средств, список которых у детей и подростков на сегодняшний день ограничен орлистатом и лираглутидом. Бариатрическая хирургия является еще одним методом лечения морбидного осложненного ожирения у подростков.

Целью лечения ожирения у детей и подростков является в краткосрочном периоде удержание значения SDS ИМТ (в течение 6-12 мес наблюдения), в долгосрочном периоде - уменьшение величины SDS ИMT, достижение «избыточной массы тела» и «нормальной массы тела», нормальное физическое и соматическое развитие ребенка, развитие самостоятельности и мотивации к самоконтролю пищевого поведения, профилактика ассоциированных с ожирением коморбидных состояний.

\section{1. Диетотерапия.}

- Для контроля массы тела у детей и подростков сожирением и избыточной массой тела рекомендовано 
формирование и поддержание норм рационального питания с учетом возрастных особенностей $[16,21,61$, 62, 64].

Уровень убедительности рекомендаций А (уровень достоверности доказательств - 1).

Комментарии. Современный тренд в диетологии детского ожирения - нормокалорийный рацион по возрасту с достаточным количеством белков, углеводов, витаминов и микроэлементов и необходимым минимумом жиров, составленный с учетом вкусовых предпочтений ребенка. Все виды диет - гипокалорийная, кетогенная, низкожировая, со сниженным гликемическим индексом и другие являются альтернативными вариантами терапии, применяются по показаниям и часто в условиях специализированных отделений.

\section{2. Физические нагрузки и профилактика}

«малоподвижного образа жизни».

- Детям и подросткам с ожирением и избыточной массой тела в возрасте от 6 до 17 лет рекомендованы ежедневные физические нагрузки умеренной и высокой интенсивности (в том числе в рамках назначения комплекса упражнений (лечебной физкультуры)) в общей сложности не менее 60 минут [22-24, 64].

Уровень убедительности рекомендаций С (уровень достоверности доказательств - 5).

- Физические нагрузки высокой интенсивности (в том числе в рамках назначения комплекса упражнений (лечебной физкультуры)) рекомендовано включать в обязательный час ежедневной физической активности и выполнять не менее 3 раз в неделю $[22,23,24]$.

Уровень убедительности рекомендаций С (уровень достоверности доказательств - 5).

Комментарии. Согласно глобальным рекомендациям BO3, адекватная физическая активность для детей и подростков в возрасте 6-17 лет подразумевает ежедневные занятия продолжительностью не менее 60 минут в день. Физическая активность свыше 60 минут в день дает дополнительные преимущества для здоровья. Рекомендованная ежедневная продолжительность физических нагрузок (60 минут и более) может складываться в течение дня из более коротких нагрузок (например, 2 раза в день по 30 минут). Минимально эффективными считаются 10-минутные периоды физической активности — от умеренной до высокой интенсивности.

- Для детей в возрасте 1-4 лет рекомендуются различные виды двигательной активности любой интенсивности в общей сложности не менее 180 минут в день для профилактики избыточной массы тела и ожирения [25].

Уровень убедительности рекомендаций С (уровень достоверности доказательств - 5).

Комментарии. Согласно рекомендациям ВОЗ от 2019 г. по вопросам физической активности, сна и малоподвижного образа жизни у детей до 5 лет, разработаны отдельные дефиниции по продолжительности физической активности для различных возрастных групп. Под физической активностью для детей младшего возраста подразумеваются различные игры: например, лежа на полу, с игрушками, ползание, гимнастика для малышей и т.д. Если ребенок еще не может ползать, рекомендуется проводить не меньше 30 минут в день лежа на животе.
- Не рекомендуется оставлять детей в возрасте от 1 до 4 лет в удерживающих устройствах более 1 ч подряд [25].

Уровень убедительности рекомендаций С (уровень достоверности доказательств - 5).

- Детям в возрасте 1 года не рекомендуется проводить время перед экраном [25].

Уровень убедительности рекомендаций С (уровень достоверности доказательств - 5).

- Детям в возрасте от 1 года до 4 лет не рекомендуется проводить более 1 ч в день перед экраном [25].

Уровень убедительности рекомендаций С (уровень достоверности доказательств - 5).

Комментарии. Рекомендации ВОЗ у детей до 5 лет лимитируют время, проводимое маленьким ребенком в удерживающих устройствах и перед экраном смартфона или телевизора (например, просмотр мультфильмов по телевизору или на переносных устройствах, игры на смартфонах и др.). Время, в течение которого ребенок находится в удерживающих устройствах, исключая сон, родителям стоит использовать для общения: читать сказки, рассказывать стихи, петь песенки. Под удерживающими устройствами имеются в виду различные люльки, коляски, детские кресла или переноски.

Кроме того, рекомендации ВОЗ 2019 г. определяют продолжительность сна у детей до 4 лет. Так, для детей до года длительность сна составляет 14-17 ч (в возрасте от 0 до 3 мес) или 12-16 ч (в возрасте от 4 до 11 мес), включая дневной сон. Для детей от 1 года до 2 лет длительность сна составляет 11-14 ч, включая дневной сон. Для детей от 3 до 4 лет длительность сна составляет 10-13 ч. Во всех возрастных группах важно соблюдение режима дня [25].

- Для детей и подростков с ожирением и избыточной массой тела с целью профилактики гиподинамии рекомендовано сокращение неактивного времени, проводимого перед экраном телевизора, монитором компьютера до 2 ч в день или меньше [24, 26-29].

Уровень убедительности рекомендаций С (уровень достоверности доказательств - 5).

Комментарии. Необходимо сокращение времени, затрачиваемого на физически неактивные виды времяпрепровождения: телевидение, видеофильмы, компьютерные игры, «брожение» по Интернету. С первого дня и на протяжении всего 1-го месяца экранное время сокращается на 30 минут, со 2-го месяца - на 45 минут, с 3-го месяца на 60 минут и т.д.

\section{3. Медикаментозная терапия}

- Использование фармакотерапии (в комбинации с изменением образа жизни) у детей и подростков с ожирением рекомендуется с 12-летнего возраста при неэффективности мероприятий, направленных на формирование здорового образа жизни, длительность которых составляла не менее 1 года [21,36].

Уровень убедительности рекомендаций А (уровень достоверности доказательств - 1).

Комментарии. Медикаментозная терапия ожирения у подростков ограничена. Препараты, разрешенные для лечения ожирения у детей старше 12 лет в мире и Российской Федерации, - это лираглутид и орлистат.

- Детям старше 12 лет с ожирением в качестве дополнения к здоровому питанию и физической 
активности при неэффективности мероприятий, направленных на формирование здорового образа жизни, длительность которых составляла не менее 1 года, может

быть рекомендована терапия лираглутидом [40, 41].

Уровень убедительности рекомендаций В (уровень достоверности доказательств - 2).

Комментарии. Лираглутид является аналогом глюкагоноподобного пептида 1 (ГПП-1). На уровне гипоталамуса лираглутид, активируя рецепторы ГПП-1, усиливает сигналы насыщения и ослабляет сигналы голода, тем самым сокращая потребление пищи. Кроме того, лираглутид глюкозозависимым путем стимулирует секрецию инсулина и уменьшает секрецию глюкагона. Эффективность и безопасность лираглутида у подростков с ожирением в возрасте 12-17 лет оценена в рандомизированном клиническом исследовании SCALE TEENS. Лираглутид снижал массу тела (в среднем на 2,7 кг по сравнению с набором веса в группе плацебо +2,1 кг), уменьшал величину SDS ИМТ больше (на 0,25), чем плацебо $(0,02)$; также отмечено большее достижение пациентами (5 и 10\%) снижения массы тела в группе лираглутида по сравнению с плацебо [40, 41].

Препарат вводится подкожно 1 раз в сутки в любое время, независимо от приема пищи, в область живота, бедра или плеча. Начальная доза составляет 0,6 мг в сутки с последующей стандартной титрацией дозы препарата согласно инструкции: доза увеличивается на 0,6 мг с интервалами не менее 1 нед. Дозу препарата следует увеличивать до тех пор, пока не будет достигнуто значение 3,0 мг (терапевтическая доза) или максимально переносимая доза. Среди побочных действий описаны диспепсические явления (снижение аппетита, тошнота, рвота, запор, диарея), которые отмечаются, как правило, в первые недели лечения, в большинстве случаев носят преходящий характер и не требуют отмены терапии.

- Детям старше 12 лет при неэффективности мероприятий, направленных на формирование здорового образа жизни, длительность которых составляла не менее 1 года, может быть рекомендован прием орлистата $[21,36]$.

Уровень убедительности рекомендаций В (уровень достоверности доказательств - 2).

Комментарии. Орлистат является ингибитором желудочной и панкреатической липаз, которые участвуют в гидролизе триглицеридов и необходимы для всасывания жиров в тонком кишечнике. В результате действия препарата нарушается расщепление пищевых жиров и уменьшается их всасывание. После отмены препарата его действие быстро прекращается, а активность липаз восстанавливается. Эффективность орлистата в комплексной терапии ожирения у подростков оценена в контролируемых клинических исследованиях. Согласно данным работам, средняя динамика веса в группе орлистата составила от +0,53 кг (12 мес терапии, 12 мес наблюдения, 539 подростков) [30], до -6,9 кг (6 мес терапии, 60 пациентов) [31]. Орлистат назначается по 1 капсуле (120 мг) перед основными приемами пищи, максимальная суточная доза составляет 360 мг (3 капсулы, по 1 капсуле 3 раза в день). Длительность лечения может составлять от 3 до 12 мес.

- Метформин не рекомендован для лечения ожирения у детей без осложнений и коморбидных состояний [32-37].
Уровень убедительности рекомендаций С (уровень достоверности доказательств - 5).

Комментарии. Применение метформина в педиатрической практике разрешено в возрастной группе старше 10 лет с установленным диагнозом СД 2 типа [32-35]. Метаанализы демонстрируют умеренный положительный эффект метформина, выражающийся преимущественно в стабилизации веса и SDS ИMT, а также улучшении метаболического профиля, инсулинорезистентности у детей и подростков с ожирением [34, 36]. Согласно данным, представленным Международным консорциумом детских эндокринологов по вопросам диагностики и лечения синдрома поликистозных яичников (СПЯ) у подростков, метформин оказывает благоприятное влияние на течение СПЯ у пациенток с избыточной массой тела и ожирением в краткосрочном периоде (6 мес). Также терапия метформином снижает частоту ановуляции и уровень тестостерона у пациенток с СПЯ без ожирения. [37]. Таким образом, терапия метформином «офф-лейбл» наиболее целесообразна в группе пациенток с гиперандрогенией и нарушениями менструального цикла, входящих в группу риска развития СПЯ.

- Не рекомендуется назначение октреотида пациентам с гипоталамическим ожирением детского возраста, поскольку применение препарата ограничено данными клинических исследований и отсутствуют данные реальной практики $[42,43]$.

Уровень убедительности рекомендаций С (уровень достоверности доказательств - 5).

- Детям с синдромом Прадера-Вилли (СПВ) может быть рекомендована терапия соматропином [66].

Уровень убедительности рекомендаций В (уровень достоверности доказательств - 2).

Комментарии. Согласно данным многочисленных исследований, терапия соматропином, особенно при назначении в раннем возрасте (до развития ожирения), приводит к улучшению антропометрических параметров и композиционного состава тела (снижению жировой и увеличению мышечной массы), что может способствовать уменьшению риска развития ожирения у этих пациентов (при условии соблюдения диеты и режима двигательной активности) [66]. Перед началом и на фоне терапии соматропином проводится оценка антропометрических параметров, состояния аденотонзиллярной системы, показателей костного возраста, значений уровня инсулиноподобного фактора роста 1 (ИФР-1), параметров углеводного обмена (исследования уровней глюкозы, иммунореактивного инсулина, гликированного гемоглобина). Учитывая потенциальный эффект соматропина на гипертрофию лимфоидной ткани носоглоточного кольца и ухудшение параметров дыхания во сне с риском развития апноэ, рекомендовано проведение полисомнографии как перед, так и на фоне терапии, особенно в первые 3-6 мес лечения соматропином. Средняя суточная доза соматропина для лечения СПВ - 1 мг/м²/сут, однако начинать терапию, особенно детям раннего возраста, рекомендовано с меньших доз (0,5 мг/м²/сут) с последующей титрацией до среднесуточной под контролем значений ИФР-1, избегая превышения референсных значений [38]. У детей с СПВ раннего возраста (до 2 лет жизни) терапия соматропином в меньших дозах (0,6 мг/м²/сут) 
показала эффективность, аналогичную таковой при использовании среднетерапевтических доз (1 мг/м²/сут), и характеризовалась меньшим количеством побочных эффектов на начальном этапе лечения [67]. Противопоказаниями для назначения соматропина у пациентов с СПВ являются тяжелое осложненное ожирение, некомпенсированный СД, тяжелая степень апноэ, активные злокачественные новообразования, психотические расстройства $[38,39,66]$.

\section{4. Хирургическое лечение.}

- Хирургические методы лечения ожирения (бариатрическая хирургия) могут быть рекомендованы подросткам с морбидным ожирением только при соблюдении следующих условий [21, 44-46].

ИМТ >35 кг/м² в сочетании с тяжелыми осложнениями (неалкогольный стеатогепатит, сахарный диабет 2 типа, синдром обструктивного апноэ во сне, болезнь Блаунта, тяжелая артериальная гипертензия).

ИMT >40 кг/M² (SDS ИMT > 4,0 для данного пола и возраста) независимо от наличия осложнений.

- Завершенное или близкое к завершению физическое развитие (частичное или полное закрытие зон роста), достижение 4-5 стадий полового развития по шкале Таннера.

- Документально подтвержденная неэффективность консервативных методов лечения ожирения в течение 12 мес в специализированных центрах.

- Отсутствие психических заболеваний и расстройств пищевого поведения (в том числе обусловленных наличием синдромальных и гипоталамических форм ожирения).

- Готовность/способность подростка и членов его семьи к длительному и регулярному послеоперационному динамическому наблюдению.

Уровень убедительности рекомендаций С (уровень достоверности доказательств - 5).

Комментарии. Хирургические методы лечения морбидного ожирения (бариатрическая хирургия) у подростков получают все большее распространение в мире в последние десятилетия. Основными преимуществами бариатрической хирургии являются быстрое снижение веса [47-51], улучшение метаболических показателей и качества жизни пациентов с морбидным ожирением [50-52]. Всем подросткам после бариатрических операций требуется мониторинг уровня витаминов и микроэлементов для своевременной диагностики их дефицита. Наиболее часто у данной группы пациентов развивается дефицит кальция и витамина D, которые при несвоевременной коррекции приводят к развитию вторичного гиперпаратиреоза и остеопороза. Часто регистрируется дефицит железа, фолиевой кислоты и других витаминов (тиамин, пиридоксин, цианокобаламин), а также жирорастворимых витаминов [50-52]. Тем не менее частое развитие стойкого дефицита витаминов и микроэлементов, высокий процент повторных оперативных вмешательств, необходимость наблюдения мультидисциплинарной командой специалистов и низкая комплаентность больных ограничивают широкое применение метаболической хирургии в лечении морбидного ожирения у подростков.

\section{4. МЕДИЦИНСКАЯ РЕАБИЛИТАЦИЯ И САНАТОРНО- КУРОРТНОЕ ЛЕЧЕНИЕ, МЕДИЦИНСКИЕ ПОКАЗАНИЯ И ПРОТИВОПОКАЗАНИЯ К ПРИМЕНЕНИЮ МЕТОДОВ МЕДИЦИНСКОЙ РЕАБИЛИТАЦИИ, В ТОМ ЧИСЛЕ ОСНОВАННЫХ НА ИСПОЛЬЗОВАНИИ ПРИРОДНЫХ ЛЕЧЕБНЫХ ФАКТОРОВ}

Специфические реабилитационные мероприятия не предусмотрены.

\section{5. ПРОФИЛАКТИКА И ДИСПАНСЕРНОЕ НАБЛЮДЕНИЕ, МЕДИЦИНСКИЕ ПОКАЗАНИЯ И ПРОТИВОПОКАЗАНИЯ К ПРИМЕНЕНИЮ МЕТОДОВ ПРОФИЛАКТИКИ}

- Детям и подросткам с избыточной массой тела и ожирением рекомендуется динамическое наблюдение с контролем антропометрических показателей, оценкой ИМТ и фактического питания [15, 21, 64].

Уровень убедительности рекомендаций С (уровень достоверности доказательств - 5).

Комментарии. Врач-педиатр наблюдает детей дошкольного и младшего школьного возраста с избыточной массой тела или метаболически неосложненным ожирением. Дети до года наблюдаются врачом-педиатром ежемесячно. Им проводят контроль антропометрических показателей, SDS ИMT. При развитии ожирения показана консультация детского эндокринолога.

Дети раннего возраста (1-3 года) наблюдаются врачом-педиатром 1 раз в 3-6 мес. При развитии ожирения также показана консультация детского эндокринолога, а при сопутствующей задержке психомоторного развития - консультация генетика.

Диспансерное наблюдение детей дошкольного и младшего школьного возраста с избыточной массой тела может проводиться как врачом-педиатром, так и врачом детским эндокринологом. Самым важным компонентом такого наблюдения по-прежнему будет оценка динамики антропометрических показателей, SDS ИМТ, оценка образа жизни ребенка и подробная беседа с родителями. В первые 3 мес необходимы ежемесячные визиты, далее (при положительной динамике) - 1 раз в 6-12 мес.

При диспансерном наблюдении подростков с ожирением показана консультация врача детского эндокринолога. Обязательным является скрининг коморбидных состояний. Диспансерное наблюдение осуществляется ежемесячно в первые 3 мес, далее (при положительной динамике) - 1 раз в 6 мес. Дети с осложненным ожирением наблюдаются у врача детского эндокринолога 1 раз в 3-6 мес. При сохранении осложнений объем обследований и наблюдений узкими специалистами определяется индивидуально.

При нормализации массы тела дети наблюдаются у врача-педиатра в декретированные сроки для здоровых детей (I группа здоровья).

- Для профилактики ожирения у детей рекомендуется активное выявление избыточной массы тела в возрасте от 2 до 9 лет и проведение школ для пациентов с избыточной массой тела и ожирением [15, 21, 64].

Уровень убедительности рекомендаций С (уровень достоверности доказательств - 5). 


\section{6. ОРГАНИЗАЦИЯ ОКАЗАНИЯ МЕДИЦИНСКОЙ ПОМОЩИ}

Показания для госпитализации в медицинскую организацию.

1. Форма - плановая; условия - стационар, дневной стационар:

а. комплексный скрининг осложнений, в отсутствие возможности обследования в амбулаторных условиях;

b. комплексное лечение с проведением Школы для пациентов с избыточной массой тела и ожирением (дневной стационар), в отсутствие возможности лечения и проведения Школы в амбулаторных условиях;

с. при планировании хирургического лечения ожирения.

2. Форма - экстренная, неотложная; условия - стационар: не предусмотрены. При развитии неотложных состояний, связанных с ухудшением течения коморбидных заболеваний (гипертонический криз, острый живот при ЖКБ, апноэ), показана госпитализация пациента в профильное отделение согласно основному неотложному состоянию.
Показания к выписке пациента из медицинской организации.

1. Форма - плановая; условия - стационар, дневной стационар:

а. проведение запланированного обследования/ лечения.

2. Форма - экстренная, неотложная; условия стационар: купирование жизнеугрожающего состояния.

\section{ДОПОЛНИТЕЛЬНАЯ ИНФОРМАЦИЯ}

Источники финансирования. Работа выполнена по инициативе авторов без привлечения финансирования.

Конфликт интересов. Авторы декларируют отсутствие явных и потенциальных конфликтов интересов, связанных с содержанием и публикацией настоящей статьи.

Участие авторов. Все авторы одобрили финальную версию статьи перед публикацией, выразили согласие нести ответственность за все аспекты работы, подразумевающую надлежащее изучение и решение вопросов, связанных с точностью или добросовестностью любой части работы.

\section{ПРИЛОЖЕНИЕ}

Таблица 3. Критерии оценки качества медицинской помощи

\begin{tabular}{|c|c|c|c|}
\hline № & Критерии качества & $\begin{array}{c}\text { Уровень } \\
\text { убедительности } \\
\text { рекомендаций }\end{array}$ & $\begin{array}{l}\text { Уровень } \\
\text { достоверности } \\
\text { доказательств }\end{array}$ \\
\hline 1 & Выполнено измерение роста и веса с оценкой SDS ИМТ & C & 5 \\
\hline 2 & Выполнено измерение артериального давления & C & 5 \\
\hline 3 & $\begin{array}{l}\text { Выполнена клиническая оценка полового развития } \\
\text { на основании шкалы Таннера }\end{array}$ & GPP & GPP \\
\hline 4 & $\begin{array}{l}\text { Выполнена оценка состояния кожных покровов, наличия } \\
\text { и характера стрий, акантоза, андрогензависимой дермопатии }\end{array}$ & GPP & GPP \\
\hline 5 & $\begin{array}{l}\text { Выполнен клинический скрининг } \\
\text { синдромальных/моногенных форм ожирения }\end{array}$ & C & 5 \\
\hline 6 & $\begin{array}{l}\text { Выполнен биохимический анализ крови по оценке нарушений } \\
\text { липидного обмена, включающий исследование уровней общего } \\
\text { холестерина, ЛПНП, ЛПВП, триглицеридов }\end{array}$ & $\mathrm{C}$ & 5 \\
\hline 7 & Выполнено определение активности АлАТ и АсАТ в крови & $\mathrm{C}$ & 5 \\
\hline 8 & Проведено УЗИ органов брюшной полости (комплексного) & $\mathrm{C}$ & 5 \\
\hline 9 & $\begin{array}{l}\text { Проведена оценка состояния углеводного обмена } \\
\text { (исследование уровня глюкозы крови натощак /проведение } \\
\text { глюкозотолерантного теста) }\end{array}$ & $\mathrm{C}$ & 5 \\
\hline 10 & $\begin{array}{l}\text { При подозрении на гипоталамическое ожирение проведена } \\
\text { МРТ головного мозга }\end{array}$ & $C$ & 5 \\
\hline 11 & $\begin{array}{l}\text { Проведена оценка фактического питания с использованием } \\
\text { 24-часового (суточного) воспроизведения питания с помощью } \\
\text { пищевого дневника }\end{array}$ & $\mathrm{C}$ & 5 \\
\hline 12 & $\begin{array}{l}\text { Выполнена консультация пациента и/или родителя по вопросам } \\
\text { рационализации питания и физической активности }\end{array}$ & C & 5 \\
\hline
\end{tabular}

Примечание: GPP — сложившаяся клиническая практика. 


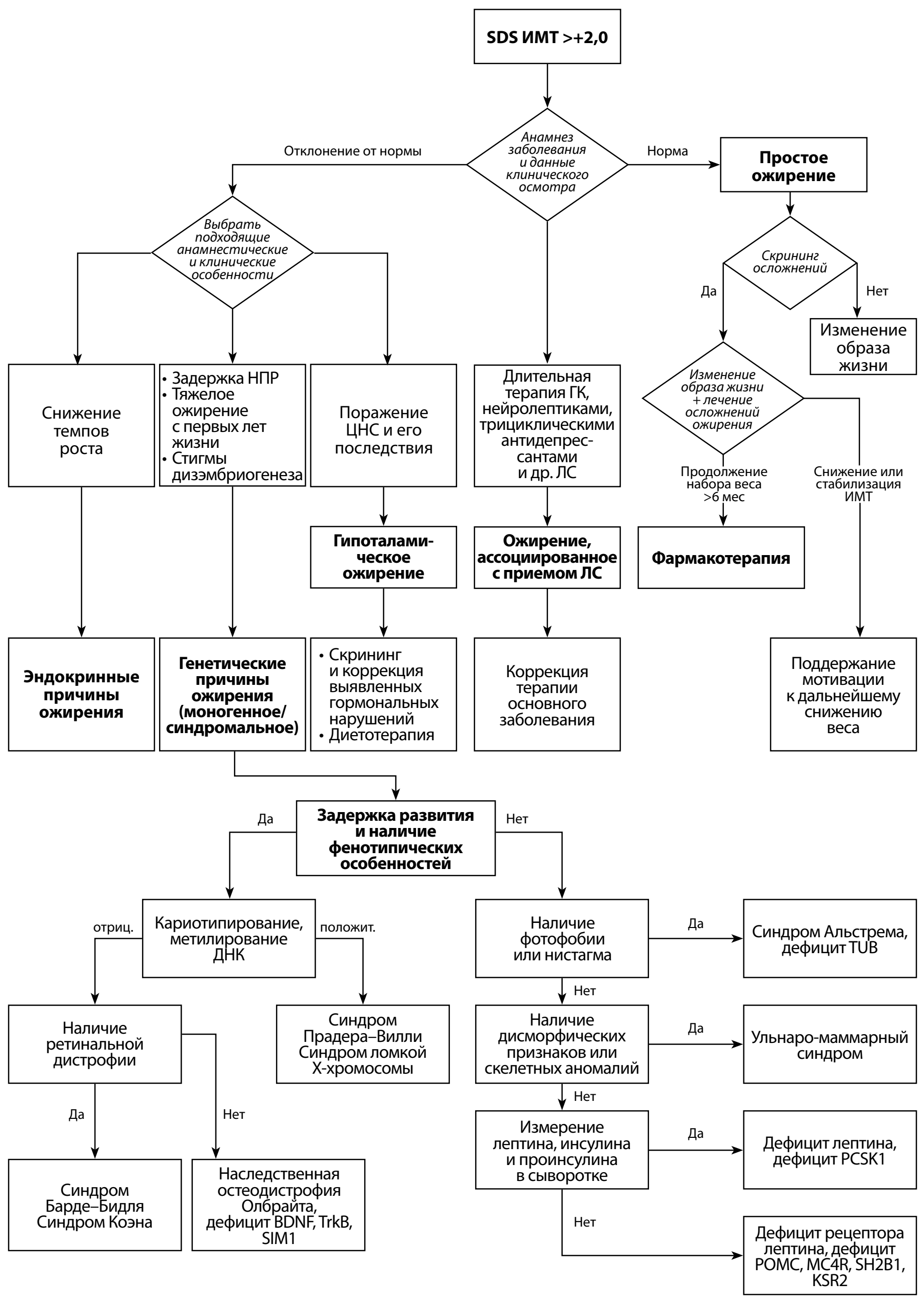




\section{СПИСОК ЛИТЕРАТУРЫ | REFERENCES}

1. Федеральные клинические рекомендации (протоколы) по ведению детей сэндокринными заболеваниями / Под ред. Дедова И.И., Петерковой В.А. - М.: Практика; 2014. 442 c. [Federal'nye klinicheskie rekomendatsii (protokoly) po vedeniyu detei s endokrinnymi zabolevaniyami. Ed. by II Dedov, VA Peterkova. Moscow: Praktika; 2014. 442 p. (In Russ.)].

2. Петеркова В.А., Васюкова О.В. К вопросу о новой классификации ожирения у детей и подростков // Проблемы Эндокринологии. 2015. — T. 61. — №2. — C. 39-45. [Peterkova VA, Vasyukova OV. About the new classification of obesity in the children and adolescents. Problems of Endocrinology. 2015;61(2):39-44. (In Russ.)]. doi: https://doi.org/10.14341/probl201561239-44

3. Петеркова В.А., Васюкова О.В. Редкие формы ожирения у детей // Лечамий врач. — 2008. - №3. - С. 29-33. [Peterkova VA, Vasyukova OV. Redkie formy ozhireniya u detei. Lechashchii vrach. 2008;3:29-33. (In Russ.)].

4. World Health Organization. [Internet]. Available from: http://www.who.int/mediacentre/factsheets/fs311/ru/

5. Васюкова О.В. Ожирение у детей и подростков: критерии диагноза // Ожирение и метаболизм. - 2019. - Т. 16. — №1. C. 70-73. [Vasyukova OV. Obesity in children and adolescents: diagnosis criteria. Obesity and metabolism. 2019;16(1):70-73. (In Russ.)] doi: https://doi.org/10.14341/omet10170

6. Latest WHO data on child obesity shows that southern European countries have the highest rate of childhood obesity/доклад Dr Joao Breda 25 ECO май 2018, Австрия. Available from: WHO/Europe | Nutrition - Latest data shows southern European countries have highest rate of childhood obesity.

7. Петеркова В.А., Нагаева Е.В., Ширяева Т.Ю. Методические рекомендации: Оченка физического развития детей и подростков. М.; 2017. 98 c. [Peterkova VA, Nagaeva EV, Shiryaeva TYu. Metodicheskie rekomendatsii: Otsenka fizicheskogo razvitiya detei i podrostkov. Moscow; 2017. 98 c. (In Russ.)].

8. Александров А.А., Бубнова М.Г., Кисляк О.А., и др. Профилактика сердечно-сосудистых заболеваний в детском и подростковом возрасте. Клинические рекомендации // Российский кардиологический журнал. - 2012. - Т. 17. — №6. - С. 1-39. [Aleksandrov AA, Bubnova MG, Kislyak OA, et al. Profilaktika serdechno-sosudistykh zabolevanii v detskom i podrostkovom vozraste. Klinicheskie rekomendatsii. Rossiiskii kardiologicheskii zhurnal. 2012;17(6):1-39. (In Russ.)].

9. Агапитов Л.И., Александров А.А., Баранов А.А., и др. Артериальная гипертензия у детей. Клинические рекомендации M3 PФ. 2016. [Agapitov LI, Aleksandrov AA, Baranov AA, et al. Arterial'naya gipertenziya u detei. Klinicheskie rekomendatsii MZ RF. 2016. (In Russ.)].

10. Molleston JP, Schwimmer JB, Yates KP, et al. Histological Abnormalities in Children with Nonalcoholic Fatty Liver Disease and Normal or Mildly Elevated Alanine Aminotransferase Levels. J Pediatr. 2014;164(4):707-713. doi: https://doi.org/10.1016/j.jpeds.2013.10.071

11. Demura S, Sato S, Kitabayashi T. Percentage of Total Body Fat as Estimated by Three Automatic Bioelectrical Impedance Analyzers. J Physiol Anthropol Appl Human Sci. 2004;23(3):93-99. doi: https://doi.org/10.2114/jpa.23.93

12. Ellis KJ. Measuring body fatness in children and young adults: Comparison of bioelectrical impedance analysis, total body electrical conductivity, and dual-energy x-ray absorptiometry. Int. J. Obes. 1996;20:866-873.

13. Johansson AG, Forslund A, Sjödin A, et al. Determination of body composition - a comparison of dual-energy x-ray absorptiometry and hydrodensitometry. Am J Clin Nutr. 1993;57(3):323-326. doi: https://doi.org/10.1093/ajcn/57.3.323

14. Malavolti M, Mussi C, Poli M, et al. Cross-calibration of eight-polar bioelectrical impedance analysis versus dualenergy X-ray absorptiometry for the assessment of total and appendicular body composition in healthy subjects aged 21-82 years. Ann Hum Biol. 2003;30(4):380-391. doi: https://doi.org/10.1080/0301446031000095211

15. Рекомендации по диагностике, лечению и профилактике ожирения у детей и подростков. - М.: Практика; 2015. 136 с. [Rekomendatsii po diagnostike, lecheniyu i profilaktike ozhireniya u detei i podrostkov. Moscow: Praktika; 2015. 136 p. (In Russ.)].
16. The Academy of Nutrition and Dietetics. Evidence Analysis Library. Pediatric Weight Management Guidelines. 2015. Available from: http://www.adaevidencelibrary.com/topic.cfm?cat=2721

17. Barlow SE. Expert Committee Recommendations Regarding the Prevention, Assessment, and Treatment of Child and Adolescent Overweight and Obesity: Summary Report. Pediatrics. 2007;120(S4):S164-S192. doi: https://doi.org/10.1542/peds.2007-2329C

18. Arslanian SA. Clamp Techniques in Paediatrics: What Have We Learned? Horm Res Paediatr. 2005;64(3):16-24. doi: https://doi.org/10.1159/000089313

19. Levy-Marchal C, Arslanian S, Cutfield W, et al. Insulin Resistance in Children: Consensus, Perspective, and Future Directions. J Clin Endocrinol Metab. 2010;95(12):5189-5198. doi: https://doi.org/10.1210/jc.2010-1047

20. Yeckel CW, Weiss R, Dziura J, et al. Validation of Insulin Sensitivity Indices from Oral Glucose Tolerance Test Parameters in Obese Children and Adolescents. J Clin Endocrinol Metab. 2004;89(3):1096-1101. doi: https://doi.org/10.1210/jc.2003-031503

21. Styne DM, Arslanian SA, Connor EL, et al. Pediatric ObesityAssessment, Treatment, and Prevention: An Endocrine Society Clinical Practice Guideline. J Clin Endocrinol Metab. 2017;102(3):709-757. doi: https://doi.org/10.1210/jc.2016-2573

22. Александров А.А., Кисляк О.А., Леонтьева И.В., Розанов В.Б. Диагностика, лечение и профилактика артериальной гипертензии у детей и подростков. Российские рекомендации (второй пересмотр) // Кардиоваскулярная терапия и профилактика. — 2009. - Т. 8. — №4 (Пр. 1). - С. 1-32. [Aleksandrov AA, Kislyak OA, Leont'eva IV, Rozanov VB. Diagnostika, lechenie i profilaktika arterial'noi gipertenzii u detei i podrostkov. Rossiiskie rekomendatsii (vtoroi peresmotr). Kardiovaskulyarnaya terapiya i profilaktika. 2009;8(4S1):1-32. (In Russ.)].

23. Александров А.А., Бубнова М.Г., Кисляк О.А., и др. Профилактика сердечно-сосудистых заболеваний в детском и подростковом возрасте. Российские рекомендации // Российский кардиологический журнал. - 2012. - Т. 6. — №98(Пр.1). C. 1-40. [Aleksandrov AA, Bubnova MG, Kislyak OA, et al. Profilaktika serdechno-sosudistykh zabolevanii v detskom i podrostkovom vozraste. Rossiiskie rekomendatsii. Rossiiskii kardiologicheskii zhurnal. 2012;6(98S1):1-40. (In Russ.)].

24. ВОЗ. Глобальные рекомендачии по физической активности для здоровья. М.: 2010.60 c. [WHO. Global'nye rekomendatsii po fizicheskoi aktivnosti dlya zdorov'ya. Moscow: 2010.60 p. (In Russ.)].

25. WHO. WHO guidelines on physical activity, sedentary behavior and sleep for children under 5 years of age. 2019.

26. Kahle E, Zijpf W, Lamb D, et al. Association Between Mild, Routine Exercise and Improved Insulin Dynamics and Glucose Control in Obese Adolescents. Int J Sports Med. 1996;17(01):1-6. doi: https://doi.org/10.1055/s-2007-972799

27. McMurray RG, Bauman MJ, Harrell JS, et al. Effects of improvement in aerobic power on resting insulin and glucose concentrations in children. Eur J Appl Physiol Occup Physiol. 2000;81 (1-2):132-139. doi: https://doi.org/10.1007/PL00013786

28. Owens S, Gutin B, Allison J, et al. Effect of physical training on total and visceral fat in obese children. Med Sci Sport Exerc. 1999;31(1):143-148. doi: https://doi.org/10.1097/00005768-199901000-00022

29. Ritenbaugh C, Teufel-Shone NI, Aickin MG, et al. A lifestyle intervention improves plasma insulin levels among Native American high school youth. Prev Med (Baltim). 2003;36(3):309-319. doi: https://doi.org/10.1016/S0091-7435(02)00015-4

30. Chanoine J-P, Hampl S, Jensen C, et al. Effect of Orlistat on Weight and Body Composition in Obese Adolescents. JAMA. 2005;293(23):2873. doi: https://doi.org/10.1001/jama.293.23.2873

31. Мельниченко Г.А., Петеркова В.А., Савельева Л.В., Зубкова Н.А. Оценка эффективности применения Ксеникала в комплексной терапии ожирения у подростков с метаболическим синдромом // Ожирение и метаболизм. 2011. - T. 8. — №4. - C. 36-42. [Mel'nichenko GA, Peterkova VA, Savel'eva LV, Zubkova NA. Evaluation of effectiveness of orlistat in complexed obesity treatment in teenagers with metabolic syndrome. Obesity and metabolism. 2011;8(4):36-42. (In Russ.)]. doi: https://doi.org/10.14341/2071-8713-5302 
32. Freemark M. Pharmacotherapy of Childhood Obesity: An evidencebased, conceptual approach. Diabetes Care. 2007;30(2):395-402. doi: https://doi.org/10.2337/dc06-1569

33. Lustig RH, Mietus-Snyder ML, Bacchetti P, et al. Insulin Dynamics Predict Body Mass Index and Z-Score Response to Insulin Suppression or Sensitization Pharmacotherapy in Obese Children. J Pediatr. 2006;148(1):23-29. doi: https://doi.org/10.1016/j.jpeds.2005.08.075

34. Lentferink YE, Knibbe CAJ, van der Vorst MMJ. Efficacy of Metformin treatment with respect to weight reduction in children and adults with obesity: a systematic review. Drugs. 2018;78(18):1887-1901. doi: https://doi.org/10.1007/s40265-018-1025-0

35. Kay JP, Alemzadeh R, Langley $G$, et al. Beneficial effects of metformin in normoglycemic morbidly obese adolescents. Metabolism. 2001;50(12):1457-1461. doi: https://doi.org/10.1053/meta.2001.28078

36. Axon E, Atkinson G, Richter B, et al. Drug interventions for the treatment of obesity in children and adolescents. Cochrane Database Syst Rev. 2016;11(11):CD012436. doi: https://doi.org/10.1002/14651858.CD012436

37. Ibáñez L, Oberfield SE, Witchel S, et al. An International Consortium Update: Pathophysiology, Diagnosis, and Treatment of Polycystic Ovarian Syndrome in Adolescence. Horm Res Paediatr. 2017;88(6):371-395. doi: https://doi.org/10.1159/000479371

38. Deal CL, Tony M, Höybye C, et al. Growth Hormone Research Society Workshop Summary: Consensus Guidelines for Recombinant Human Growth Hormone Therapy in Prader-Willi Syndrome. J Clin Endocrinol Metab. 2013;98(6):E1072-E1087. doi: https://doi.org/10.1210/jc.2012-3888

39. Stafler P, Wallis C. Prader-Willi syndrome: who can have growth hormone? Arch Dis Child. 2008;93(4):341-345 doi: https://doi.org/10.1136/adc.2007.126334

40. Kelly AS, Auerbach P, Barrientos-Perez M, et al. A Randomized, Controlled Trial of Liraglutide for Adolescents with Obesity. N Engl J Med. 2020;382(22):2117-2128. doi: https://doi.org/10.1056/NEJMoa1916038

41. Mastrandrea LD, Witten L, Carlsson Petri KC, et al. Liraglutide effects in a paediatric (7-11 y) population with obesity: A randomized, double-blind, placebo-controlled, short-term trial to assess safety, tolerability, pharmacokinetics, and pharmacodynamics. Pediatr Obes. 2019;14(5):e12495. doi: https://doi.org/10.1111/ijpo.12495

42. Lustig RH, Hinds PS, Ringwald-Smith K, et al. Octreotide Therapy of Pediatric Hypothalamic Obesity: A Double-Blind, PlaceboControlled Trial. J Clin Endocrinol Metab. 2003;88(6):2586-2592. doi: https://doi.org/10.1210/jc.2002-030003

43. Lustig RH, Rose SR, Burghen GA, et al. Hypothalamic obesity caused by cranial insult in children: Altered glucose and insulin dynamics and reversal by a somatostatin agonist. J Pediatr. 1999;135(2):162-168. doi: https://doi.org/10.1016/S0022-3476(99)70017-X

44. Lustig RH, Rose SR, Burghen GA, et al. IPEG Guidelines for Surgical Treatment of Extremely Obese Adolescents. J Laparoendosc Adv Surg Tech. 2009;19(1):xiv-xvi. doi: https://doi.org/10.1089/lap.2009.9997

45. Fried $M$, Hainer $V$, Basdevant $A$, et al. Interdisciplinary European Guidelines on Surgery of Severe Obesity. Obes Facts. 2008;1 (1):52-59. doi: https://doi.org/10.1159/000113937

46. Pratt JSA, Browne A, Browne NT, et al. ASMBS pediatric metabolic and bariatric surgery guidelines, 2018. Surg Obes Relat Dis. 2018;14(7):882-901. doi: https://doi.org/10.1016/j.soard.2018.03.019

47. Black JA, White B, Viner RM, Simmons RK. Bariatric surgery for obese children and adolescents: a systematic review and meta-analysis. Obes Rev. 2013;14(8):634-644. doi: https://doi.org/10.1111/obr.12037

48. Inge TH, Zeller MH, Jenkins TM, et al. Perioperative Outcomes of Adolescents Undergoing Bariatric Surgery. JAMA Pediatr. 2014;168(1):47. doi: https://doi.org/10.1001/jamapediatrics.2013.4296

49. Göthberg G, Gronowitz E, Flodmark C-E, et al. Laparoscopic Rouxen-Y gastric bypass in adolescents with morbid obesity - Surgical aspects and clinical outcome. Semin Pediatr Surg. 2014;23(1):11-16. doi: https://doi.org/10.1053/j.sempedsurg.2013.10.015

50. Inge TH, Courcoulas AP, Jenkins TM, et al. Weight Loss and Health Status 3 Years after Bariatric Surgery in Adolescents. N Engl J Med. 2016;374(2):113-123. doi: https://doi.org/10.1056/NEJMoa1506699

51. Olbers T, Beamish AJ, Gronowitz E, et al. Laparoscopic Roux-en-Y gastric bypass in adolescents with severe obesity (AMOS): a prospective, 5-year, Swedish nationwide study. Lancet Diabetes Endocrinol. 2017;5(3):174-183. doi: https://doi.org/10.1016/S2213-8587(16)30424-7
52. Paulus GF, de Vaan LEG, Verdam FJ, et al. Bariatric Surgery in Morbidly Obese Adolescents: a Systematic Review and Meta-analysis. Obes Surg. 2015;25(5):860-878 doi: https://doi.org/10.1007/s11695-015-1581-2

53. Васюкова О.В. Инсулин, лептин, липиды и периферические ростовые факторы при ожирении у детей: Дис. .... канд. мед. наук. - М.; 2006. 24 c. [Vasyukova OV. Insulin, leptin, lipidy i perifericheskie rostovye faktory pri ozhirenii u detei. [dissertation] Moscow: 2006. 24 p. (In Russ.)].

54. Петеркова В.А., Ремизов О.В. Ожирение в детском возрасте // Ожирение и метаболизм. - 2004. - Т. 1. — №1. C. 17-23. [Peterkova VA, Remizov OV. Ozhirenie v detskom vozraste. Obesity and metabolism. 2004;1(1):17-23. (In Russ.)] doi: https://doi.org/10.14341/2071-8713-5174

55. Ивашкин В.Т., Маевская М.В., Павлов Ч.С., и др. Клинические рекомендации по диагностике и лечению неалкогольной жировой болезни печени Российского общества по изучению печени и Российской гастроэнтерологической ассоциации // Российский журнал гастроэнтерологии, гепатологии, колопроктологии. - 2016. - Т. 26. — №2. - C. 24-42. [lvashkin VT, Mayevskaya MV, Pavlov ChS, et al. Diagnostics and treatment of non-alcoholic fatty liver disease: clinical guidelines of the Russian Scientific Liver Society and the Russian gastroenterological association. Russian Journal of Gastroenterology, Hepatology, Coloproctology. 2016;26(2):24-42. (In Russ.)]. doi: https://doi.org/10.22416/1382-4376-2016-26-2-24-42

56. Mayer-Davis EJ, Kahkoska AR, Jefferies C, et al. ISPAD Clinical Practice Consensus Guidelines 2018: Definition, epidemiology, and classification of diabetes in children and adolescents. Pediatr Diabetes. 2018;19:7-19. doi: https://doi.org/10.1111/pedi.12773

57. Mayer-Davis EJ, Kahkoska AR, Jefferies C, et al. 2. Classification and Diagnosis of Diabetes: Standards of Medical Care in Diabetes - 2020. Diabetes Care. 2020;43(S1):S14-S31. doi: https://doi.org/10.2337/dc20-S002

58. World Health Organization. Definition and diagnosis of diabetes mellitus and intermediate hyperglycaemia: report of a WHO/IDF consultation. WHO; IDF: 2006

59. Сомнология и медицина сна. Национальное руководство памяти А.М. Вейна и Я.И. Левина / Под ред. Полуэктова М.Г. М.: Медфорум, 2016. [Comnologiya i meditsina sna. Natsional'noe rukovodstvo pamyati AM Veina i Yal Levina. Ed. by Poluektov MG. Moscow: Medforum; 2016. (In Russ.)].

60. Takahara M, Katakami N, Kaneto H, Noguchi M, Shimomura I. Distribution of the Matsuda Index in Japanese healthy subjects. J Diabetes Investig. 2013;4(4):369-371. doi: https://doi.org/10.1111/jdi.12056

61. Mead E, Brown T, Rees K, et al. Diet, physical activity and behavioural interventions for the treatment of overweight or obese children from the age of 6 to 11 years. Cochrane Database Syst Rev. 2017;2017(6). doi: https://doi.org/10.1002/14651858.CD012651

62. Павловская Е.В., Сурков А.Г., Шилина Н.М., и др. Современные подходы к диетотерапии ожирения у детей // Bonросы детской диетологии. - 2016. - Т. 14. — №1. — C. 41-46. [Pavlovskaya EV, Surkov AG, Shilina NM, et al. Modern approaches to diet therapy for obesity in children. Vopr Det Dietol. 2016;14(1):41-46. (In Russ.)]. doi: https://doi.org/10.20953/1727-5784-2016-1-41-46

63. Кедринская А.Г., Образцова Г.И., Леонова И.А. Компонентный состав у детей с избыточной массой тела и ожирением // Российский педиатрический журнал. - 2018. - Т. 21. №2. - C. 73-77. [Kedrinskaya AG, Obraztsova GI, Leonova IA. Component composition of the body in children with excessive body mass and obesity. Russ Pediatr J. 2019;21(2):73-77. (In Russ.)]. doi: https://doi.org/10.18821/1560-9561-2018-21-2-73-77

64. Holm J-C, Gamborg M, Bille DS, et al. Chronic care treatment of obese children and adolescents. Int J Pediatr Obes. 2011;6(3-4):188-196. doi: https://doi.org/10.3109/17477166.2011.575157

65. Ивашкин В.Т., Маев И.В., Баранская Е.К., и др. Рекомендации Российской гастроэнтерологической ассоциации по диагностике и лечению желчнокаменной болезни // Российский журнал гастроэнтерологии, гепатологии, колопроктологии. - 2016. T. 26. — №3. — C. 64-80. [Ivashkin VT, Maev IV, Baranskaya EK, et al. Rekomendatsii Rossiiskoi gastroenterologicheskoi assotsiatsii po diagnostike i lecheniyu zhelchnokamennoi bolezni. Russian Journal of Gastroenterology, Hepatology, Coloproctology. 2016;26(3):64-80. (In Russ.)]. doi: https://doi.org/10.22416/1382-4376-2016-26-3-64-80 
66. Passone CDGB, Franco RR, Ito SS, et al. Growth hormone treatment in Prader-Willi syndrome patients: systematic review and meta-analysis. BMJ Paediatr Open. 2020;4(1):e000630. doi: https://doi.org/10.1136/bmjpo-2019-000630
67. Scheermeyer E, Harris M, Hughes I, et al. Low dose growth hormone treatment in infants and toddlers with Prader-Willi syndrome is comparable to higher dosage regimens. Growth Horm IGF Res. 2017;34(1):1-7. doi: https://doi.org/10.1016/j.ghir.2017.03.001

Рукопись получена: 19.08.2021. Одобрена к публикации: 25.08.2021. Опубликована online: 30.10 .2021

\section{ИНФОРМАЦИЯ ОБ АВТОРАХ [AUTHORS INFO]}

*Окороков Павел Леонидович, к.M.H. [Pavel L. Okorokov, MD]; адрес: Россия, 117036, Москва, ул. Дмитрия Ульянова, д. 11 [address: 11 Dm. Ulyanova street, 117036, Moscow, Russia]; eLibrary SPIN: 6989-2620; ORCID: https://orcid.org/0000-0001-9834-727X; e-mail: pokorokov@gmail.com

Безлепкина Ольга Борисовна, д.м.н. [Olga B. Bezlepkina, MD]; eLibrary SPIN: 3884-0945;

ORCID: https://orcid.org/0000-0001-9621-5732; e-mail: olgabezlepkina@mail.ru

Богова Елена Ахсарбековна, к.M.H. [Elena A. Bogova, MD]; eLibrary SPIN: 2273-4237;

ORCID: https://orcid.org/0000-0001-7445-4871, e-mail: eabogova@gmail.com.

Болотова Нина Викторовна, д.м.н. [Nina V. Bolotova, MD]; eLibrary SPIN: 5061-1600; ORCID: https://orcid.org/0000-0002-8148-526X; e-mail: kafedranv@mail.ru

Васюкова Ольга Владимировна, К.M.н. [Olga V. Vasyukova, MD]; eLibrary SPIN: 6432-3934;

ORCID: https://orcid.org/0000-0002-9299-1053; e-mail: o.vasyukova@mail.ru

Гирш Яна Владимировна, д.м.н. [Yana V. Girsh, MD]; eLibrary SPIN: 6683-8810;

ORCID: https://orcid.org/0000-0003-0283-2428; e-mail: yanaef@yandex.ru

Кияев Алексей Васильевич, д.м.н. [Alexey V. Kiyaev, MD, PhD]; eLibrary SPIN: 7092-7894;

ORCID: https://orcid.org/0000-0002-5578-5242; e-mail: thyroend@mail.ru

Кострова Ирина Борисовна [Irina B. Kostrova]; eLibrary SPIN: 9224-7047;

ORCID: https://orcid.org/0000-0003-0112-3785; e-mail: ira-kostrova@mail.ru

Малиевский Олег Артурович, д.м.н. [Oleg A. Malievskiy, MD]; eLibrary SPIN: 6813-5061;

ORCID: https://orcid.org/0000-0003-2599-0867; e-mail: malievsky@list.ru

Михайлова Евгения Геннадьевна, К.M.н. [Evgeniia G. Mikhailova, MD]; eLibrary SPIN:935-1806;

ORCID: https://orcid.org/0000-0002-2213-6334; e-mail: e.mikhailova13@yandex.ru

Петеркова Валентина Александровна, д.М.н. [Valentina A. Peterkova, MD]; eLibrary SPIN: 4009-2463;

ORCID: 0000-0002-5507-4627; e-mail: peterkovava@hotmail.com

Петряйкина Елена Ефимовна, д.М.H. [Elena E. Petryaykina, MD]; eLibrary SPIN: 5997-7464;

ORCID: http://orcid.org/0000-0002-8520-2378; e-mail: lepet_morozko@mail.ru

Таранушенко Татьяна Евгеньевна, д.М.н., профессор [Tatiana E. Taranushenko, MD]; elibrary SPIN: 4777-0283;

ORCID: https://orcid.org/0000-0003-2500-8001; e-mail: tetar@rambler.ru

Храмова Елена Борисовна, д.М.н., профессор [Elena B. Khramova, MD, PhD, professor]; eLibrary SPIN 2462-3440;

ORCID: https://orcid.org/0000-0001-8968-3925; e-mail: doctor.khramova@gmail.com

\section{ЦИТИРОВАТЬ:}

Петеркова В.А., Безлепкина О.Б., Болотова Н.В., Богова Е.А., Васюкова О.В., Гирш Я.В., Кияев А.В., Кострова И.Б., Малиевский О.А., Михайлова Е.Г., Окороков П.Л., Петряйкина Е.Е., Таранушенко Т.Е., Храмова Е.Б. Клинические рекомендации «Ожирение у детей» // Проблемы эндокринологии. - 2021. - Т. 67. — №5. - С. 67-83. doi: https://doi.org/10.14341/probl12802

\section{TO CITE THIS ARTICLE:}

Peterkova VA, Bezlepkina OB, Bolotova NV, Bogova EA, Vasyukova OV, Girs YV, Kiyaev AV, Kostrova IB, Malievskiy OA, Mikhailova EG, Okorokov PL, Petryaykina EE, Taranushenko TE, Khramova EB. Clinical guidelines «Obesity in children». Problems of Endocrinology. 2021;67(5):67-83. doi: https://doi.org/10.14341/probl12802 